\title{
A INTERFACE GRÁFICA DE UM APLICATIVO PARA BUSCA DE EVENTOS
}

\author{
Alcir Heidemann (1); \\ Claudia Regina Batista (2); \\ Adhemar Maria do Valle Filho (3); \\ (1) Universidade Federal de Santa Catarina, Graduação em Design \\ e-mail: alcirheidemann@gmail.com \\ (2) Universidade Federal de Santa Catarina, Dra. \\ e-mail: claudia.batista@ufsc.br \\ (2) Universidade do Valle do Itajaí, Dr. \\ e-mail: adhe.valle@gmail.com
}

\begin{abstract}
RESUMO
Este artigo apresenta o design da interface gráfica do "Rolê" - um aplicativo para smartphones que tem a finalidade de realizar busca de eventos culturais. Este projeto teve como alicerce as áreas do Design, Ergonomia de Interface e Usabilidade. O método de projeto adotado para guiar o processo de design foi proposto sob o enfoque da Engenharia de Usabilidade pelo American Institutes for Research.
\end{abstract}

\section{ABSTRACT}

This paper shows the interface design for Rolê"- a mobile application to search cultural events. This project was based in the areas of Design, Interface Ergonomics and Usability. The methodology that guided the project is the focus of Usability Engineering and it was proposed by American Institutes for Research.

\section{INTRODUÇÃO}

Para um público que gosta de frequentar eventos culturais e de entretenimento, está sendo desenvolvido o "Rolê" - um aplicativo para smartphones - que possibilitará a busca dos eventos de maneira rápida, fácil e eficiente. Para esse aplicativo havia a necessidade de criar a interface gráfica; e tal fato gerou a demanda para o presente estudo, cujo ponto de partida deu-se a partir da seguinte questão de pesquisa: Como propiciar ao usuário uma interação fácil/intuitiva com o aplicativo de busca de eventos culturais?

Como objetivo geral propôs-se realizar o design da interface gráfica interativa para o aplicativo para busca de eventos "Rolê"; e foram definidos os seguintes objetivos específicos: 
- Planejar a estrutura das telas e a disposição dos conteúdos, representando graficamente como wireframes.

- Adequar o estilo gráfico, a paleta cromática, a tipografia, entre outros elementos visuais, conforme o perfil do público-alvo e o conceito do aplicativo.

- Criar um ícone de acesso ao aplicativo.

- Considerar os pressupostos da ergonomia e usabilidade de interfaces.

- Avaliar a interface proposta com a participação de usuários com perfil similar ao público alvo do aplicativo.

Este estudo foi realizado no projeto de conclusão do curso de Design | UFSC e foi guiado pelo método de projeto voltado ao desenvolvimento de interfaces gráficas digitais proposto pelo American Institutes for Research, sob o enfoque da Engenharia de Usabilidade que é apresentado na sequência.

\section{O MÉTODO DE PROJETO}

O método de projeto proposto pelo American Institutes for Research e suas principais etapas estão apresentadas na figura 1.

Figura 1 - Design de Interface com o usuário

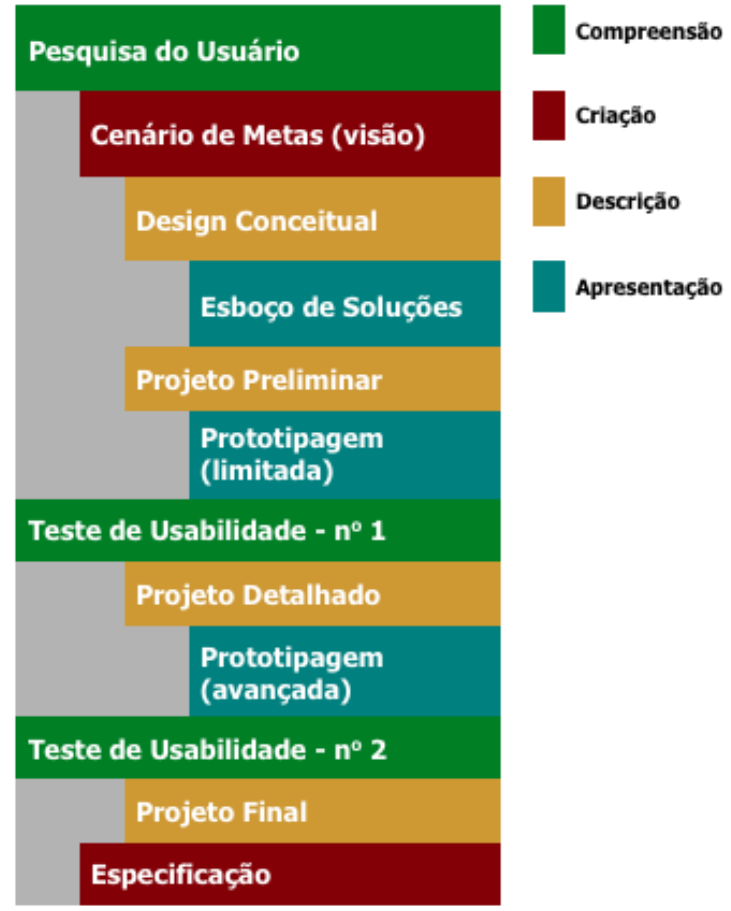

Fonte: American Institutes for Research (2007).

Neste método de projeto, as etapas são destacadas com 4 cores distintas, onde cada cor corresponde a um tipo de comportamento necessário para o designer envolver-se na realização das etapas projetuais, tais como:

- Verde: exige a compreensão dos dados obtidos;

- Vermelho: estágio de criação;

- Ocre: destinado a descrição da nova interface;

- Azul: voltado a apresentação dos modelos tais como layouts, protótipos.

Conforme o American Institutes for Research (2007), o método de projeto prevê as seguintes etapas: 
- Pesquisa do usuário: etapa destinada a levantar dados sobre o usuário; esta ação é necessária porque o projetista deve compreender as características, as preferências, as expectativas e os níveis de experiência do usuário durante a interação com a interface.

- Cenário de Metas (visão): etapa destinada à criação de um quadro de metas que se pretende atingir, elencando os componentes e as funcionalidades que a interface deve conter (obs.: é expresso com verbo no futuro ou no infinitivo).

- Design Conceitual: etapa destinada à descrição do conceito da interface, ou seja, faz-se a representação da "nova interface" por meio de suas características gerais. $O$ design conceitual tem o objetivo de produzir princípios de projeto para o novo produto; deve ser suficiente para satisfazer as exigências do usuário e diferenciar a nova interface de outras em produtos digitais concorrentes.

- Esboço de Soluções: etapa destinada à apresentação dos registros das ideias em forma de esboços/sketches ou outra forma de representação gráfica. O projetista gera soluções para a interface.

- Projeto Preliminar: seleciona-se a melhor solução proposta no estágio anterior e, nesta etapa, faz-se a descrição da interface a partir de um modelo (layout).

- Prototipagem (limitada): etapa destinada à construção do protótipo da interface e, neste estágio do projeto, o protótipo pode ser de baixa complexidade.

- Teste de Usabilidade - $\mathbf{n}^{\circ}$ 1: etapa destinada a testar o protótipo (de baixa complexidade) para verificar a usabilidade da interface e identificar se os componentes propiciam interação eficaz. A partir dos resultados do teste de usabilidade, torna-se possível compreender como foi o desempenho dos participantes da testagem e se há necessidade de realizar ajustes na interface para aprimorá-la.

- Projeto Detalhado: etapa destinada à descrição completa e detalhada da interface, com maior grau de refinamento.

- Prototipagem (avançada): etapa destinada a construção do protótipo avançado da interface.

- Teste de Usabilidade - $\mathbf{n}^{\circ}$ 2: etapa destinada a testar o protótipo avançado para verificar a usabilidade da interface e identificar se os componentes propiciam interação eficaz. A partir dos resultados do teste de usabilidade, torna-se possível compreender como foi o desempenho dos participantes da testagem e se há necessidade de realizar ajustes na interface para aprimorá-la. Projeto Final: após realizar os ajustes e correções necessárias identificadas do teste de usabilidade, nesta etapa faz-se a descrição da versão final da interface.

- Especificação: etapa destinada a especificação para implementação da interface.

$\mathrm{Na}$ sequência, apresentam-se os resultados obtidos nas etapas previstas no método de projeto "Design de Interface com o usuário", do American Institutes for Research (2007).

\subsection{Pesquisa do usuário}

O entendimento dos desejos e necessidades do usuário tem amplo valor para uma interface. Para auxiliar nesse entendimento, Cybis, Betiol e Faust (2010, p. 130) propõem que exista um envolvimento do usuário no desenvolvimento da interface. Preece, Sharp e Rogers (2005, p. 300) destacam que esse envolvimento é importante por ser a única maneira de se certificar que os usuários serão ouvidos.

De modo a compreender as características, as preferências, as expectativas e os níveis de experiência do usuário durante a interação com a interface, fez-se a opção em aplicar um questionário a um público com perfil similar aos futuros usuários do aplicativo, sendo que a faixa etária foi definida entre 16 e 30 anos. Essa faixa etária é a que participa mais ativamente de eventos e atividades culturais. $O$ questionário foi aplicado via internet no período de 10/10/2015 à 25/10/2015 e 42 participantes da pesquisa enviaram suas respostas. 
A partir dos dados obtidos através da aplicação do questionário foi possível criar uma persona (ver quadro 1) para melhor entender os hábitos do usuário. As Personas são um agregado de usuários comuns (de determinada marca ou produto), que tem seus atributos e comportamentos resumidos em um único personagem. (ANDERSON, MCREE, WILSON, 2010, p. 196)

\section{Quadro 1 - Características e expectativas da Persona}

\begin{tabular}{|c|c|}
\hline 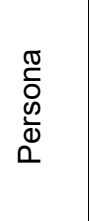 & $\begin{array}{c}\text { Nome: Karen } \\
\text { Sexo: Feminino } \\
\text { Idade: } 23 \text { anos } \\
\text { Estado Civil: Solteira } \\
\text { Ocupação: Estudante }-5^{\text {a }} \text { fase de Cinema }\end{array}$ \\
\hline$\underset{\frac{\pi}{\pi}}{\stackrel{\frac{\pi}{\pi}}{\frac{\pi}{2}}}$ & $\begin{array}{c}\text { Karen tem paixão pela cultura e arte. Em sua rotina passa boa parte do tempo na } \\
\text { universidade. No tempo restante, ela reveza entre fazer os trabalhos da faculdade } \\
\text { e assistir filmes, ler livros ou assistir uma peça de teatro com os amigos; sempre } \\
\text { que tem oportunidade vai a festas ou shows. }\end{array}$ \\
\hline 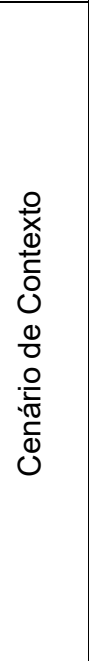 & $\begin{array}{l}\text { Karen, assim como a maioria dos jovens de sua idade, é bem informada sobre } \\
\text { tecnologias e tendências; ela possui vários aplicativos para smartphone, inclusive } \\
\text { alguns permitem a busca de programas para o fim de semana. O que a deixa } \\
\text { desanimada é o fato de possuir diferentes aplicativos para cinema instalados no } \\
\text { seu smartphone, pois cada rede de cinema possui seu aplicativo próprio. Dessa } \\
\text { forma, as consultas/pesquisas são isoladas, e não é possível encontrar todos os } \\
\text { filmes em cartaz num único app. Alguns dispõem a função "compra de ingressos", } \\
\text { enquanto outros não; assim ela precisa acessar o website da rede para efetuar a } \\
\text { compra. Com relação ao teatro, festas e shows, ela possui outros aplicativos para } \\
\text { esses fins. Frequentemente, precisar usar o Facebook, pois os aplicativos que } \\
\text { possui para procura desses tipos de eventos são ineficazes. Além disso, todos } \\
\text { esses aplicativos instalados acabam ocupando muita memória no seu smartphone. } \\
\text { Em relação a interface, Karen frequentemente tem problemas para encontrar o que } \\
\text { procura nos aplicativos, e precisa realizar muitos cliques para chegar onde deseja, } \\
\text { o que a deixa aborrecida. Por fim, o uso de poucas cores, ícones e ilustrações faz } \\
\text { com que a navegação seja monótona e desinteressante para ela. }\end{array}$ \\
\hline 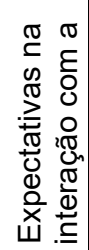 & $\begin{array}{c}\text { Karen espera que com o aplicativo Rolê ela possa ter uma experiência otimizada, } \\
\text { onde poderá pesquisar os mais diversos tipos de eventos de forma inteligente e } \\
\text { sem necessitar de diversos apps diferentes. Ela espera que a interface seja fácil, } \\
\text { simples e eficaz, além de entretenimento e diversão. Isso inclui menos telas e } \\
\text { cliques, mais cores, uso de ícones, botões, tipografia e outros elementos que } \\
\text { enriquecerão a experiência. }\end{array}$ \\
\hline
\end{tabular}

Fonte: Heidemann (2016, p. 42).

\subsection{Cenário de Metas (visão)}

O cenário de Metas consiste em elencar as metas que se pretende atingir em relação a qualidade, as funcionalidades e ao desempenho que a interface deve conter.

Para auxiliar na definição das metas, fez-se a opção pelo benchmarking competitivo para comparar aplicativos similares em busca de informações sobre os recursos presentes nas interfaces, e a partir disso os pontos positivos e negativos em relação as funções, design e navegabilidade da interface. Foram comparados 3 similares: Vamos, EventBrite e Catraca Livre.

Após cruzar as informações sobre os concorrentes, o objetivo do aplicativo e os dados sobre as preferências do usuário, foram definidas as metas para o desenvolvimento da 
interface para as funcionalidades do aplicativo e em relação aos Usuários, conforme pode-se observar os quadros 2 e 3, respectivamente.

Quadro 2 - Metas para o Design da Interface em relação as funcionalidades do aplicativo

\begin{tabular}{|c|c|}
\hline Funcionalidades do Aplicativo & Metas para a Interface \\
\hline $\begin{array}{l}\text { Realizar buscas em diferentes tipos de } \\
\text { eventos de forma personalizada. }\end{array}$ & $\begin{array}{l}\text { Disponibilizar campo de entrada de dados } \\
\text { (para que o usuário possa digitar o tema da } \\
\text { busca), botões, filtros e menu de navegação } \\
\text { pelas categorias de eventos. }\end{array}$ \\
\hline $\begin{array}{l}\text { Apresentar resultado da busca fornecendo } \\
\text { informações sobre os eventos. }\end{array}$ & $\begin{array}{l}\text { Disponibilizar informação verbal escrita ou } \\
\text { através de comunicação visual, de forma } \\
\text { clara, simples, com legibilidade e fácil } \\
\text { decodificação do significado da mensagem. }\end{array}$ \\
\hline $\begin{array}{l}\text { Possibilitar ao usuário a compra de ingressos } \\
\text { pelo aplicativo de forma integral e segura. }\end{array}$ & $\begin{array}{l}\text { Disponibilizar hiperlink para sistemas de } \\
\text { compras seguras (por exemplo: Paypal). }\end{array}$ \\
\hline $\begin{array}{c}\text { Navegação rápida através das telas para } \\
\text { acessar conteúdos e funcionalidades do } \\
\text { aplicativo. }\end{array}$ & $\begin{array}{c}\text { Implementar as páginas/telas em } \\
\text { conformidade com os padrões web para } \\
\text { mobile da W3C. }\end{array}$ \\
\hline $\begin{array}{l}\text { Propiciar interação com outros usuários do } \\
\text { aplicativo. }\end{array}$ & $\begin{array}{l}\text { Disponibilizar hiperlinks (vínculos com base de } \\
\text { dados), botões, campos de entrada e saída de } \\
\text { dados. }\end{array}$ \\
\hline Integração com redes sociais. & $\begin{array}{l}\text { Disponibilizar botões e ícones com hiperlinks } \\
\text { ligando o aplicativo às redes sociais. }\end{array}$ \\
\hline $\begin{array}{c}\text { Ligação com GPS, possibilitando mostrar } \\
\text { localização do usuário, trajeto e distância até } \\
\text { determinado evento. }\end{array}$ & $\begin{array}{c}\text { Incorporar mapas do Google Maps na } \\
\text { interface. }\end{array}$ \\
\hline Interação do usuário com os eventos & $\begin{array}{l}\text { Disponibilizar botões e ícones que } \\
\text { possibilitarão salvar e/ou curtir os eventos, e } \\
\text { campos de texto para comentários. }\end{array}$ \\
\hline $\begin{array}{l}\text { Possibilitar o feedback do usuário sobre o } \\
\text { app. }\end{array}$ & $\begin{array}{l}\text { Disponibilizar página com campos de texto } \\
\text { para comentários e ranking para que o usuário } \\
\text { avalie o app em uma nota de } 1 \text { á } 5 .\end{array}$ \\
\hline
\end{tabular}

Fonte: Heidemann (2016, p. 46).

\section{Quadro 3 - Metas para o Design da Interface em relação aos Usuários}

\begin{tabular}{|c|c|}
\hline Usuários do Aplicativo & Metas para a Interface \\
\hline $\begin{array}{c}\text { Maior índice de usuários na faixa etária entre } \\
15 \text { a } 30 \text { anos. }\end{array}$ & $\begin{array}{c}\text { Adotar estilo visual gráfico compatível com } \\
\text { público jovem, com uso de cores, tipografia, } \\
\text { imagens e formas que expressem as } \\
\text { preferências desta faixa etária. }\end{array}$ \\
\hline $\begin{array}{c}\text { Experiência do usuário: há familiaridade com } \\
\text { navegação em dispositivos móveis e boa } \\
\text { experiência no uso de aplicativos para } \\
\text { smartphones voltados a diversas finalidades. }\end{array}$ & $\begin{array}{c}\text { Propiciar ações de interação entre o usuário- } \\
\text { app de forma simples e rápida. Ícones sobre } \\
\text { botões podem ser usados para sintetizar } \\
\text { informações textuais. }\end{array}$ \\
\hline Expectativas do usuário. & $\begin{array}{c}\text { - Propiciar usabilidade e comunicação eficaz. } \\
\text { - Minimizar ao máximo possível o uso de } \\
\text { propaganda, criando uma interface limpa e } \\
\text { agradando o usuário. }\end{array}$ \\
\hline
\end{tabular}

Fonte: Heidemann (2016, p. 47). 


\subsection{Design Conceitual}

Com base nos dados levantados nas etapas anteriores, foi possível estabelecer o conceito da interface para o aplicativo Rolê: divertido; jovem; simples; inovador.

O conceito "divertido" foi criado principalmente com base na persona e na proposta do app, pois um aplicativo sobre eventos está intimamente ligado à diversão e ao entretenimento. A interface engloba diversão, sobretudo, através da paleta de cores, que deve ser forte e vívida. As cores são recursos relevantes no design de qualquer produto, e o seu uso da maneira correta pode impressionar e influenciar nas decisões do usuário. Além disso, para conceber essa interface divertida, foram utilizados ícones, imagens, ilustrações e tipografia, escolhidos de maneira a representar o conceito.

O público-alvo é jovem, dessa forma a interface precisa fazer jus a esse público. $O$ conceito "jovem" foi desenvolvido através de inúmeros recursos gráficos. Os ícones e botões foram trabalhados em um estilo flat e moderno. Além disso, a navegabilidade é de extrema importância aqui e as transições e efeitos reforçam o conceito jovem da interface.

A simplicidade, por sua vez, foi obtida através do estudo e organização dos recursos e conteúdo das telas que compõem o aplicativo, evitando o excesso de informação e permitindo apenas que o essencial esteja presente. Os textos, ícones, menus, botões e outros recursos gráficos estão dispostos de maneira que simplifique a interface e os processos entre ela e o usuário.

Por último, o conceito "inovador" busca diferenciar/destacar a interface do aplicativo Rolê de seus concorrentes. Buscou-se alcançar este propósito através do uso de novos recursos, funcionalidades e design visual. Além de contemplarem os outros conceitos, os elementos da interface, tais como, as cores, os ícones, os botões e todos os demais recursos gráficos foram planejados de modo que a interface expresse o "inovador".

\subsection{Esboço de Soluções}

Nesta etapa foram criadas soluções para a interface gráfica e na sequência são apresentados os registros das ideias. Este processo foi desenvolvido em três estágios: soluções para a estrutura da tela (wireframes), planejamento dos ícones e design visual da interface.

\subsubsection{Wireframes}

Antes de criar soluções para a camada visual da interface, foi necessário idealizar a estrutura das telas. Para tanto, a partir da arquitetura do sistema que aponta o número de telas e seus respectivos conteúdos, foram elaborados os wireframes.

O wireframe é um esquema gráfico elaborado para indicar onde devem estar localizados os elementos da interface (textos, imagens, objetos interativos, menu de navegação, etc.), ou seja, mostra a estruturação do conteúdo de cada tela e a funcionalidade de uma aplicação, sem deter-se ao aspecto visual gráfico.

Foram exploradas várias propostas e a figura 1 apresenta um exemplo da produção realizada. 
Figura 1 - Exemplos de Wireframes do app Rolê

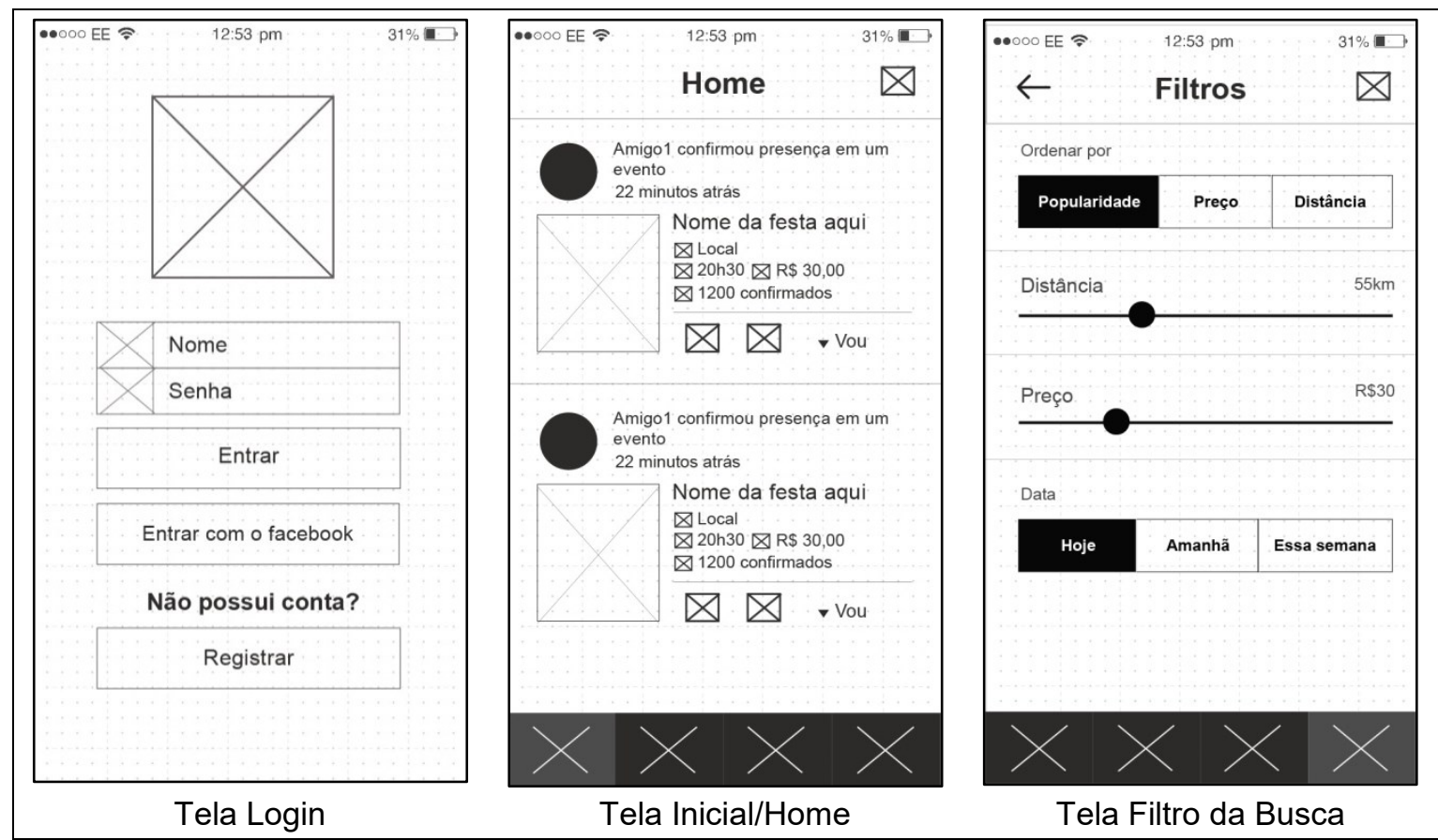

Fonte: Heidemann (2016, p.54-55).

\subsubsection{Geração de Soluções para os Ícones da Interface}

Em uma interface para mobile, onde a área é bastante restrita, o uso de ícones, além de auxiliar na percepção e compreensão, facilitando a navegação e ajuda a poupar espaço. Também, contribuem visualmente para a interface, criando um design mais dinâmico e criativo.

A figura 2 apresenta o ícone de acesso ao app Rolê; ele está disposto num quadrado com cantos arredondados conforme o padrão dos ícones do sistema iOS, da fabricante Apple. Adotou-se esse padrão porque inicialmente o aplicativo estará disponível para iOS.

Figura 2 - Ícone de acesso ao app Rolê

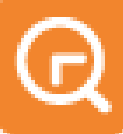

Fonte: Heidemann (2016, p.60).

$\mathrm{Na}$ figura 3 são apresentados os ícones desenvolvidos para a interface do app Rolê. Eles procuram seguir esse motivo visual comum e agregar os conceitos definidos para o projeto da interface. 
Figura 3 - Os Ícones desenvolvidos para a interface do app Rolê.
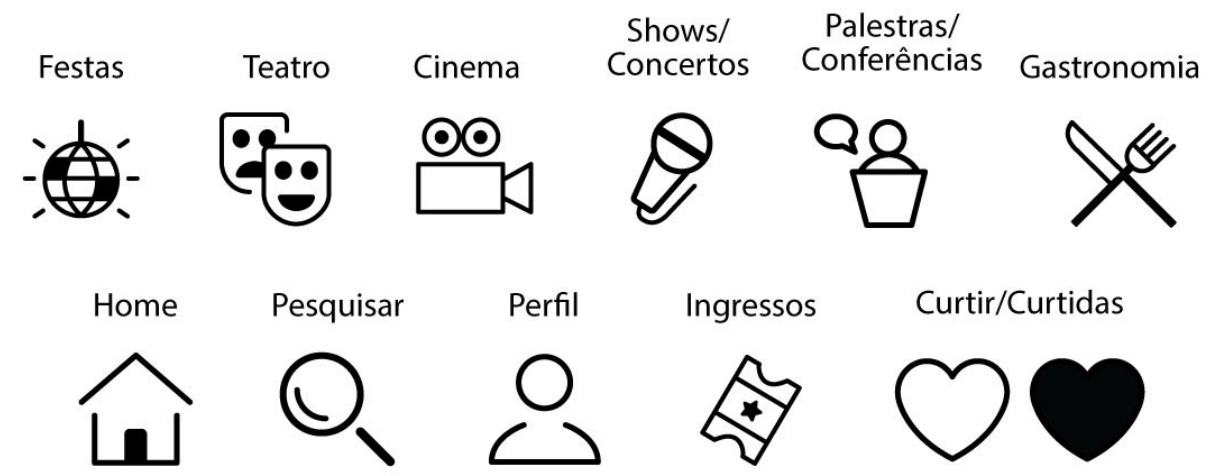

Comentar/Comentários Favoritos/Favoritar Facebook Twitter
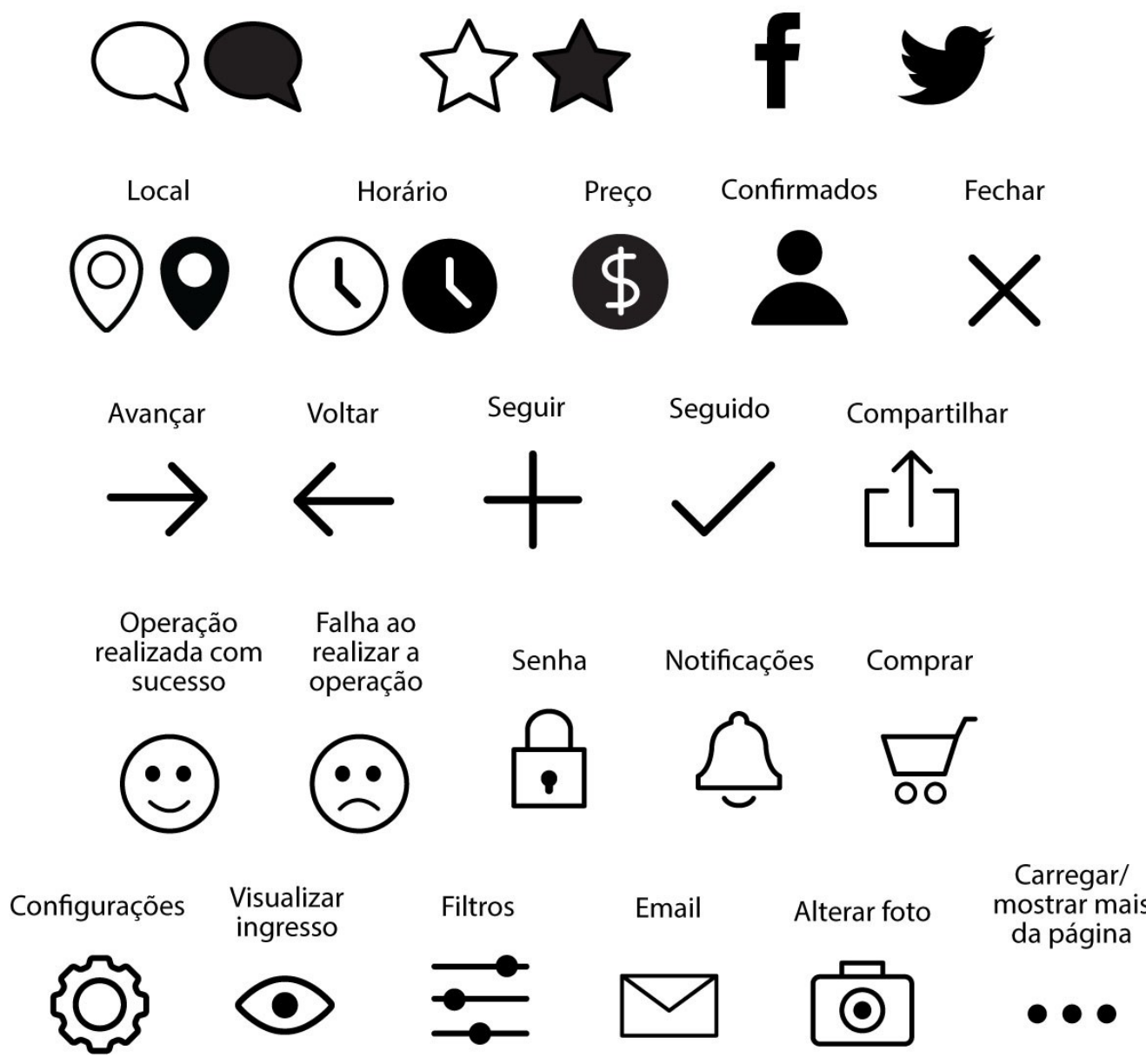

Fonte: Heidemann (2016, p.59).

\subsubsection{Geração de Soluções para o Design Visual da Interface}

Neste estágio foram elaborados diversos estudos para o design visual da interface do app Rolê e na figura 4 pode-se observar exemplos de algumas soluções geradas. 
Figura 4 - Exemplos de Wireframes do app Rolê

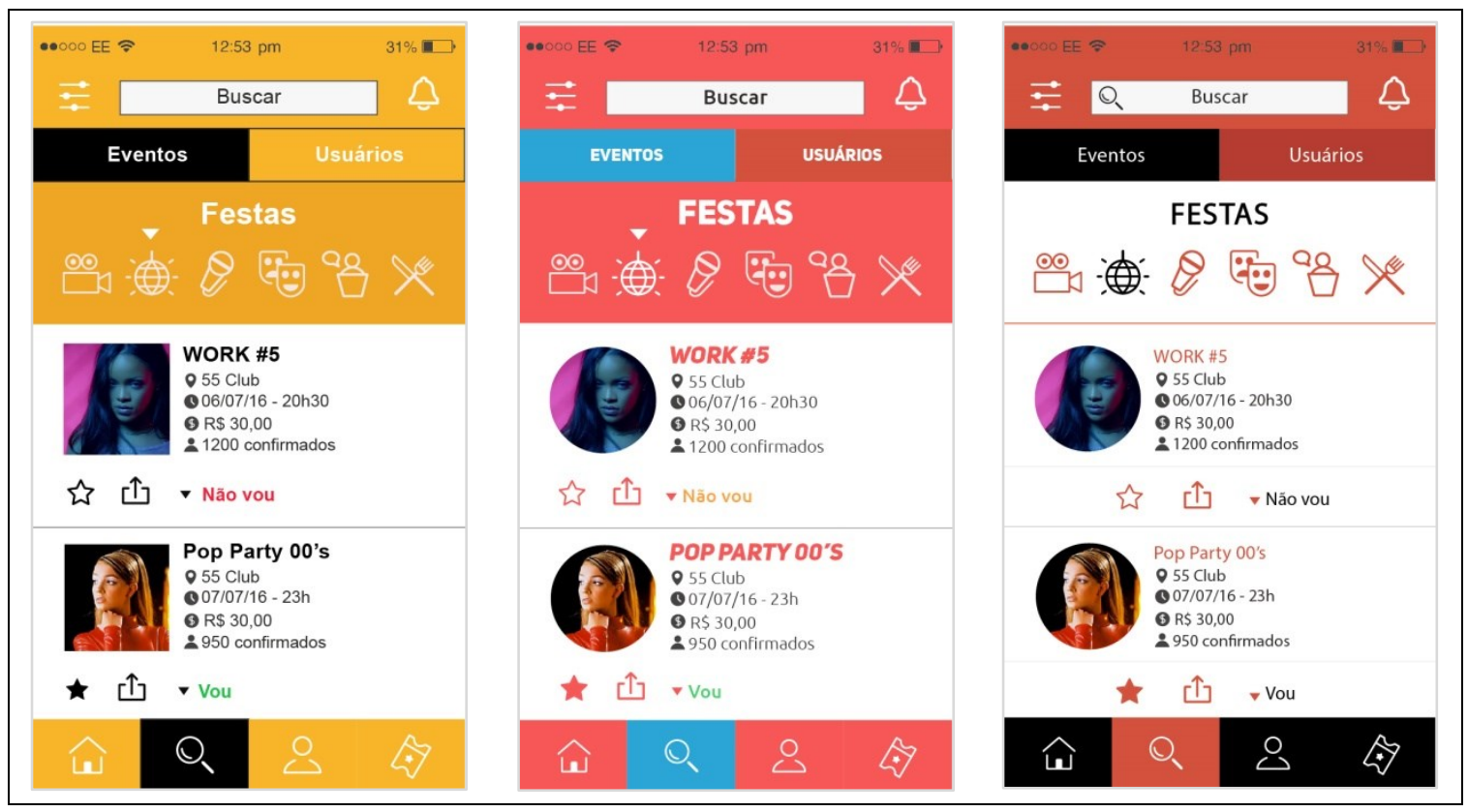

Fonte: Heidemann (2016, p.64).

\subsection{Projeto Preliminar}

Após explorar ideias, partiu-se para a seleção e refinamento da melhor solução; exemplos de layouts de algumas telas são apresentados na figura 5.

Figura 5 - Exemplos de telas do app Rolê

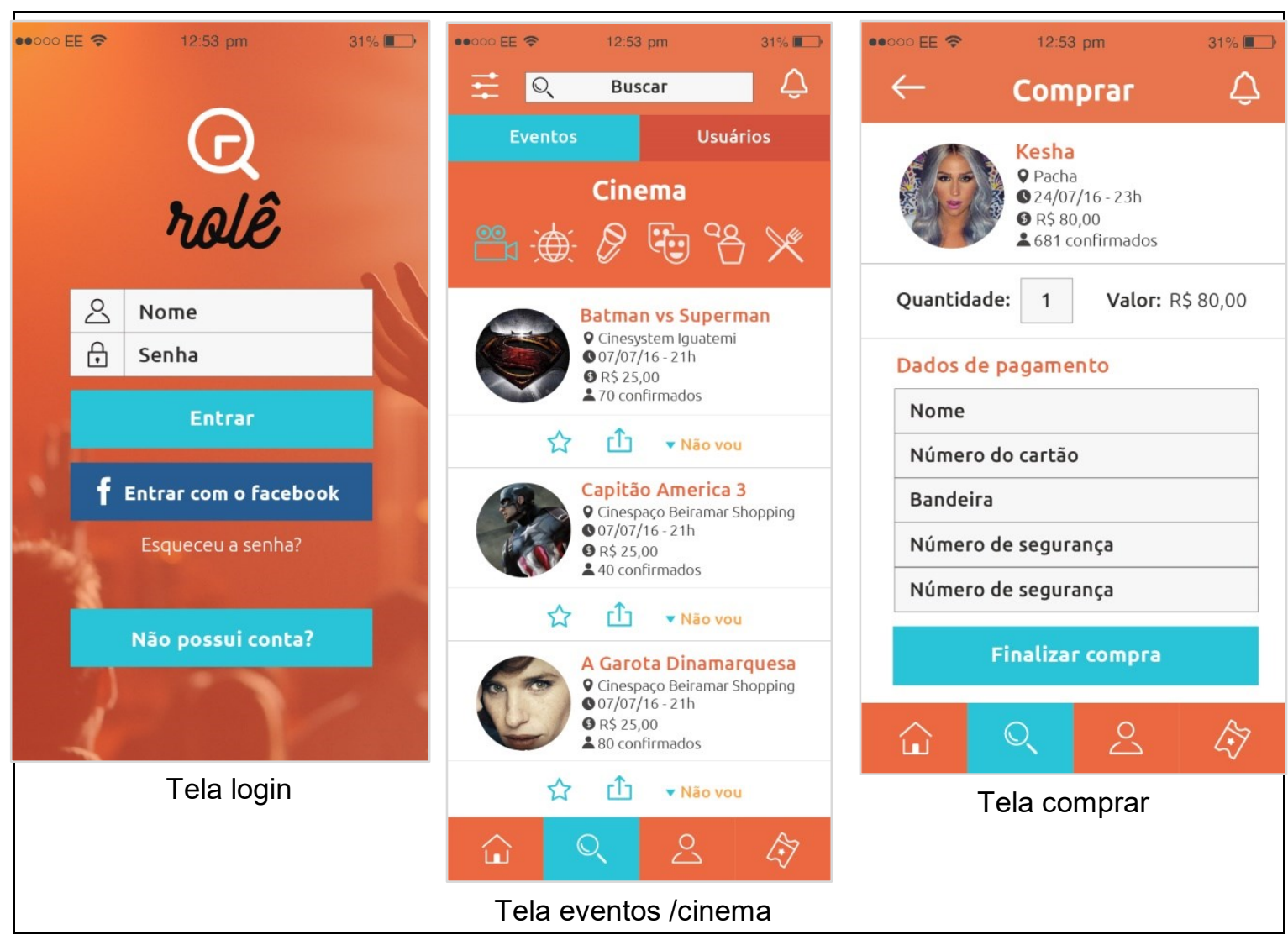


Fonte: Heidemann (2016, p.66-76).

\subsection{Prototipagem (limitada)}

De acordo com Preece, Sharp e Rogers (2005, p. 261), um protótipo é "uma representação limitada de um design que permite aos usuários interagir com ele e explorar a sua conveniência". Ele serve para inúmeras funções, desde testar a viabilidade da ideia até criar testes e avaliações para possíveis usuários.

O protótipo da interface do app "Rolê" foi construído utilizando o MarvelApp, uma ferramenta que possibilita a criação de protótipos online de forma gratuita. Ele permite adicionar fotos das diferentes telas do app, criar links e interações simples entre elas, deste modo fazendo-as simularem um aplicativo real. Isso acontece de forma limitada, pois no protótipo não é possível adicionar campos de texto e outros recursos mais complexos.

O protótipo pode ser acessado através do endereço: https://marvelapp.com/1ig856h

\subsection{Teste de Usabilidade $-\mathrm{n}^{\circ} 1$}

O teste de usabilidade é a etapa destinada a testar o protótipo para verificar a usabilidade da interface e identificar se os componentes propiciam interação eficaz.

A ideia por trás dos testes é bem simples. De acordo com Krug (2014), os participantes do teste recebem tarefas para executarem com um protótipo (ou sistema operacional). O desempenho dos participantes do teste é observado, registrado e analisado de modo a identificar se as metas de usabilidade foram alcançadas.

\subsubsection{Metodologia para o Teste de Usabilidade da Interface do app Rolê}

O teste de usabilidade teve como objetivos verificar:

- o grau de empatia do usuário em relação a interface do aplicativo;

- a compreensibilidade e legibilidade do ícone de acesso e dos demais ícones do app;

- a legibilidade dos elementos textuais;

- a clareza e intuitividade durante a navegação;

- a facilidade em realizar as funções disponíveis no aplicativo;

- a agradabilidade da paleta cromática;

- a eficácia da composição visual, ou seja, se a disposição e a quantidade de elementos gráficos na tela facilitam o processo de comunicação e interação entre o usuário e o aplicativo.

Foram estabelecidas as seguintes etapas para o teste:

- informar o usuário sobre o contexto do projeto e orientá-lo sobre as tarefas que ele deverá realizar;

- fornecer um celular para o usuário interagir com o protótipo do aplicativo;

- registrar as ações do usuário e cronometrar o tempo durante a interação;

- aplicar o questionário (ver apêndice 1) após o término da interação para o usuário expressar sua opinião sobre o aplicativo.

- analisar os dados obtidos durante o teste;

- indicar as recomendações para aprimoramento da interface (se necessário).

Durante o teste foram utilizados estes recursos:

- Celular.

- Cronômetro.

Métricas:

- Tempo de execução da tarefa. 
- Taxa de finalização da tarefa.

Foram definidas 10 tarefas para o usuário realizar durante a interação com o protótipo:

$1^{\text {a) }}$ Crie uma nova conta.

$2^{\mathrm{a}}$ ) Veja as últimas notificações.

$3^{\text {a) }}$ Visualize seu perfil.

$4^{\mathrm{a}}$ ) Encontre a página de ingressos e visualize um ingresso.

$5^{a}$ ) Busque e entra na página de um show ou concerto.

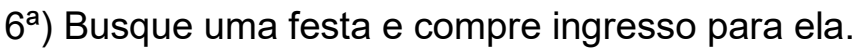

$7^{\mathrm{a}}$ ) Busca uma palestra ou conferência e compartilhe ela no Facebook.

$8^{a}$ ) Encontre os filtros de buscas de eventos.

$\left.9^{a}\right)$ Veja os eventos que um amigo vai participar.

$\left.10^{a}\right)$ Encontre a tela de busca de usuários.

O teste de usabilidade do aplicativo Rolê foi aplicado presencialmente no período de 09/05/2016 à 14/05/2016 e contou com 15 participantes. Eles representam uma parcela do público-alvo.

Após o término da interação com o protótipo, os participantes do teste responderam ao questionário (apêndice 1). A partir dos resultados1 obtidos na aplicação do teste foram identificadas algumas dificuldades durante a interação, os participantes também deram sugestões/contribuições para melhorar a interface e a interação. Deste modo, foram realizadas algumas correções e ajustes na interface de modo a aprimorá-la.

\subsection{Projeto Detalhado}

\subsubsection{A paleta de cores da interface do aplicativo Rolê}

Para a interface do app Rolê buscou-se uma paleta de cores que exprimisse os conceitos: divertido, jovem, simples e inovador.

O laranja foi definido como a principal cor da interface. Ambrose e Harris (2009, p. 112) definem o laranja como chamativo, lúdico, quente e extrovertido, o que corresponde muito bem ao conceito de diversão e jovialidade do app. Além disso, é uma cor atraente para os adolescentes e jovens, público-alvo do projeto.

A cor laranja foi aplicada em todas as telas, sempre em pequenos detalhes, nunca de modo excessivo, pois sendo uma cor chamativa e vibrante, poderia deixar a interface muito carregada ou exagerada.

Juntamente com o laranja foram escolhidas outras cores, as quais foram empregadas de forma secundária. A primeira delas é o azul, cor complementar do laranja. As cores complementares são as que estão opostas no círculo cromático e sua combinação resulta em um design vibrante e de alto contraste. (AMBROSE, HARRIS, 2009, p. 20). O uso da combinação laranja + azul proporciona exatamente esses efeitos, o que torna a interface mais interessante e também de fácil compreensão, especialmente pelo uso do azul em detalhes que precisam ser evidenciados (como em botões) e para "marcar" em que botão/função o usuário está navegando. O azul em tom claro, como o utilizado na interface, também está associado com jovialidade (AMBROSE, HARRIS, 2009, p. 118).

\footnotetext{
1 Os resultados do teste de Usabilidade não foram apresentados neste artigo devido a restrição de número de páginas; mas podem ser encontrados na íntegra em Heidemann (2016).
} 
As outras cores designadas foram o branco, cinza (escuro) e o preto; o emprego delas justifica-se, sobretudo, pelo fato de serem cores neutras. O preto, de acordo com Ambrose e Harris (2009, p. 128) possui um grande contraste quando utilizado em combinação com o branco, mas também funciona bem com quase todas as outras cores que não forem muito escuras. No entanto, ele é uma cor séria e elegante, o que não possui relação com os conceitos definidos para a interface. Por esse motivo, ele é empregado em poucos detalhes, sendo o seu uso quase inteiramente restrito à texto.

O branco, por sua vez, simboliza simplicidade e possui um ótimo contraste com as cores preto, cinza (escuro) azul e laranja. (AMBROSE, HARRIS, 2009, p 125). É utilizado na interface principalmente como cor de fundo, em ícones e texto quando a cor de fundo é laranja ou azul.

Figura 5 - A paleta de cores e os códigos hexadecimais

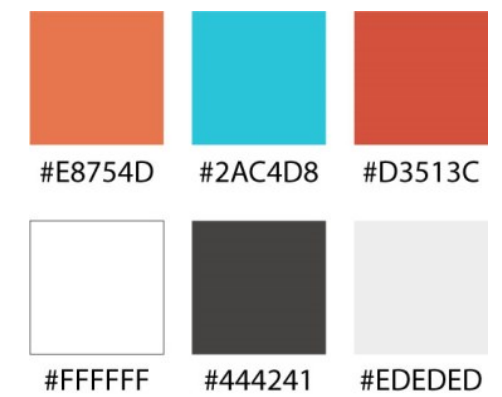

Fonte: Heidemann (2016, p.147).

\subsubsection{Tipografia}

A tipografia escolhida para a interface do app Rolê foi a Ubuntu. Trata-se de uma fonte gratuita sem serifa. Em mídias com tipos em tamanho pequeno, como é o caso da interface do app Rolê, é recomendado que sejam utilizadas fontes sem serifa, pois as serifas podem comprometer a legibilidade quando em tamanho muito pequeno (LIDWELL, HOLDEN, BUTLER, 2010, p. 148).

A escolha da tipografia se deu também pelo fato de ser uma fonte moderna e ter um aspecto "divertido", causado por conta de suas bordas ligeiramente arredondadas. Além disso, essa família tipográfica possui uma boa quantidade de variações, assim não sendo necessário recorrer a outras tipografias e criando uma identidade coesa e organizada. A Ubuntu apresenta boa legibilidade, é fácil de ser lida mesmo em um tamanho pequeno.

Figura 6 - Família tipográfica Ubuntu

$$
\text { The Ubuntu Font Family }
$$

The Ubuntu Font Family

\section{The Ubuntu Font Family}

\section{The Ubuntu Font Family}

Fonte: Canonical (2016) 


\subsubsection{Diagramação}

A diagramação consiste em distribuir os elementos gráficos no espaço limitado da página/tela. Trabalha-se o alinhamento de textos e imagens, buscando harmonia e equilíbrio entre a massa de conteúdo informacional.

No design da interface do app Rolê foi utilizado um alinhamento central. Os ícones, botões e textos foram centralizados dentro do espaço que Ihes é delimitado. Uma exceção são os blocos de texto, que estão alinhados a esquerda, por conta do fluxo da leitura (da esquerda para a direita).

$O$ alinhamento e posicionamento dos elementos foram criados com base em um grid próprio para o iPhone 5s, que possibilitou o desenvolvimento de um layout organizado e padrão.

\subsection{Especificação}

Para implementar a interface do app Rolê será utilizado uma abordagem híbrida adotando os padrões abertos como HTML 5, CSS, JavaScript mais os recursos de hardware disponíveis nos kits de desenvolvimento de software nativo do sistema operacional iOS.

O HTML 5, CSS, JavaScript permitem que o aplicativo seja portável para diferentes plataformas (dispositivos e sistemas operacionais). O aplicativo em HTML5 é multiplataforma porque ele está limitado apenas à compatibilidade dos navegadores. Porém, utilizando os recursos de um aplicativo nativo (do iOS) pode-se fazer uso de elementos da interface nativa e é possível acessar os diversos sensores que o aplicativo suporta como câmera, GPS, SMS, etc. Além disso, utilizar aplicativo nativo torna-se possível comercializar essa aplicação através de um repositório como Apple Store. Aplicativos nativos costumam ter um desempenho ainda melhor. (DEVMEDIA, 2016).

\section{CONSIDERAÇÕES FINAIS}

O aplicativo Rolê está em fase de desenvolvimento e modificações/ajustes poderão ocorrer, sem deixar de lado a essência estética e funcional do sistema.

A prototipagem (avançada) e o Teste de Usabilidade - $n^{\circ} 2$ são etapas previstas no método de projeto "Design de Interface com o usuário", do American Institutes for Research (2007), que ainda não foram realizadas neste projeto. Torna-se necessário construir um protótipo mais aprimorado ou uma versão beta do aplicativo com o intuito de verificar o desempenho dos usuários em relação às funcionalidades e, também, a eficiência do mecanismo de busca do aplicativo.

Por fim, destaca-se que neste estudo buscou-se desenvolver uma interface de fácil entendimento para os usuários. Por isso, voltou-se a atenção nas características, expectativas e experiência do usuário; trabalhou-se para manter a consistência das telas; alcançar a simplicidade; propiciar facilidade na navegação e na interação. Tais elementos constituem critérios básicos que podem promover a usabilidade do aplicativo Rolê.

\section{REFERÊNCIAS BIBLIOGRÁFICAS}

AMBROSE, Gavin; HARRIS, Paul. Cor. Rio de Janeiro: Bookman, 2009.

American Institutes for Research. Design de Interface com o Usuário. Disponível on-line em http://www.air.org/contact.aspx, acesso em 15/02/2007.

ANDERSON, Jonathan; MCREE, John; WILSON, Robb. Effective UI. O'Reilly Media, 2010. 
CANONICAL. Ubuntu Font Family. Disponível em http://font.ubuntu.com/about/, acesso em 04/03/2016.

CYBIS, Walter; BETIOL, Adriana Holtz; FAUST, Richard. Ergonomia e usabilidade: conhecimentos, métodos e aplicações. São Paulo: Novatec, 2007.

DEVMEDIA. Projetando e criando aplicativos para dispositivos móveis. Disponível em http://www.devmedia.com.br/projetando-e-criando-aplicativos-para-dispositivos-moveis/30671, acesso em 03/06/2016.

HEIDEMANN, Alcir. Design da interface gráfica para o "Rolê": um aplicativo para busca de eventos. Florianópolis, 2016. 182f. Monografia (Graduação em Design) - Design, Universidade Federal de Santa Catarina.

KRUG, Steve. Não me faça pensar!: uma abordagem de bom senso à usabilidade na web. Rio de Janeiro: Alta Books, 2014.

LIDWELL, William; HOLDEN, Kristina; BUTLER, Jill. Princípios Universais do Design. Porto Alegre: Bookman, 2010.

MARVEL. Free mobile \& web prototyping. Disponível on-line em https://marvelapp.com/. Acesso em 20 de março de 2016.

ROGERS, Yvonne; SHARP, Helen; PREECE, Jennifer. Design de Interação: Além da Interação Humano-Computador. Porto Alegre: Bookman, 2005.

\section{Apêndice 1 - Questionário do Teste de Usabilidade}

Descrição: Após a realização do teste e usabilidade, peço-lhe que responda o questionário a seguir. Seu feedback é importante para a melhoria do projeto.

\begin{tabular}{|l|}
\hline Parte 1 - Geral. \\
\hline $\begin{array}{l}\text { 1 - Qual é a sua opinião sobre a aparência das } \\
\text { telas do aplicativo? (assinale quantas opções } \\
\text { desejar) }\end{array}$ \\
\hline Bonita/Agradável \\
\hline Divertida \\
\hline Inovadora \\
\hline Simples \\
\hline Jovem \\
\hline Séria/Profissional \\
\hline Normal \\
\hline Ruim \\
\hline Péssima \\
\hline Amadora \\
\hline Outro \\
\hline $\begin{array}{l}\text { 2 - Qual é a sua opinião sobre a paleta de cores } \\
\text { utilizada? (assinale quantas desejar) }\end{array}$ \\
\hline Bonita/Agradável \\
\hline Divertida \\
\hline Inovadora \\
\hline Simples \\
\hline Jovem \\
\hline Séria/Profissional \\
\hline Normal \\
\hline Ruim \\
\hline Muito carregada \\
\hline Pouco contraste \\
\hline Péssima \\
\hline Amadora \\
\hline Outro \\
\hline $\mathbf{3}$ - Qual é a sua opinião sobre a \\
organização/estrutura do conteúdo? \\
\hline Organizada \\
\hline Confusa \\
\hline $\mathbf{4}$ - O texto estava legível? Se a resposta for \\
\hline
\end{tabular}

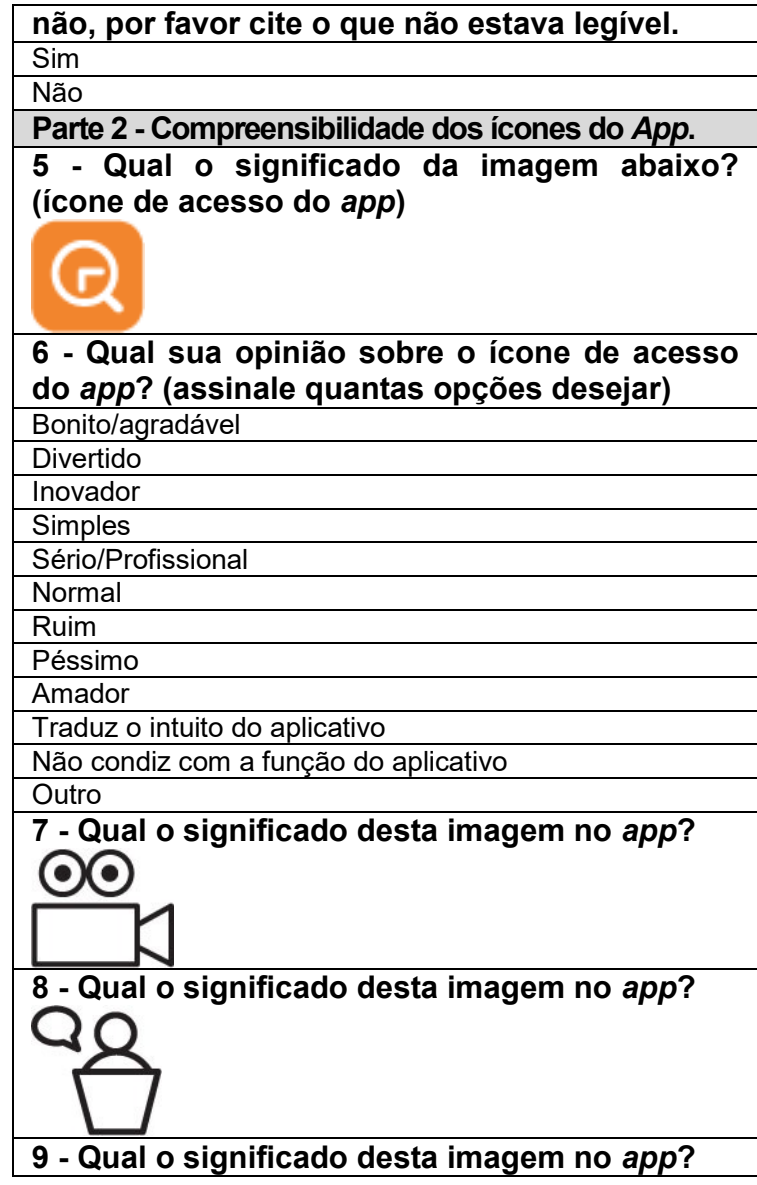




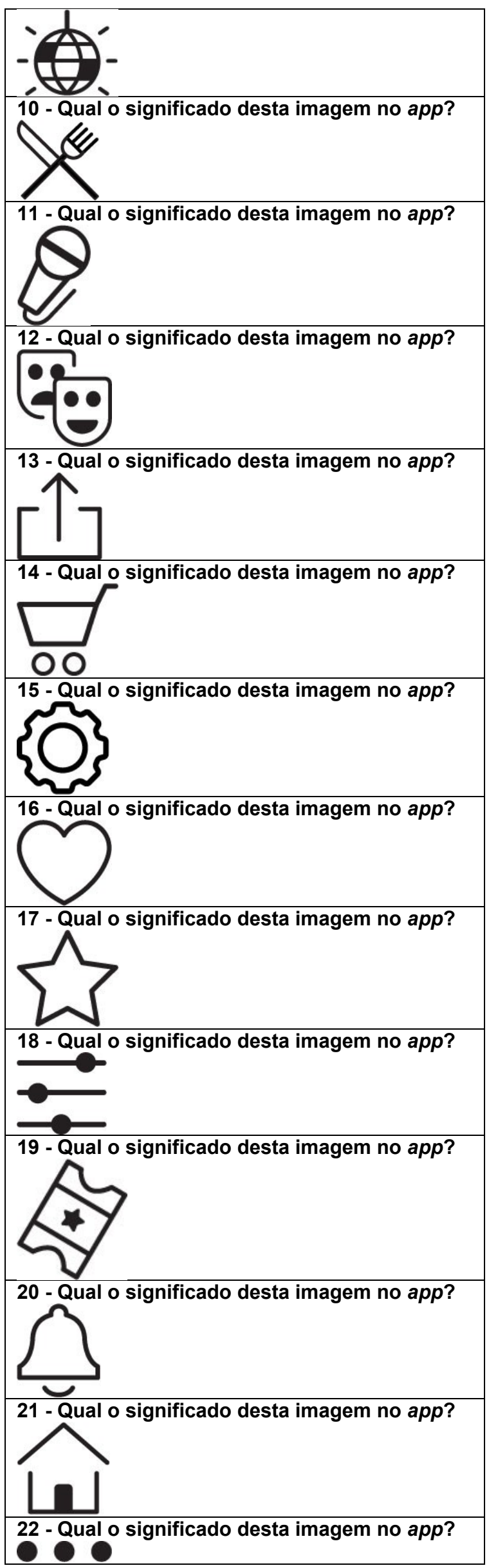

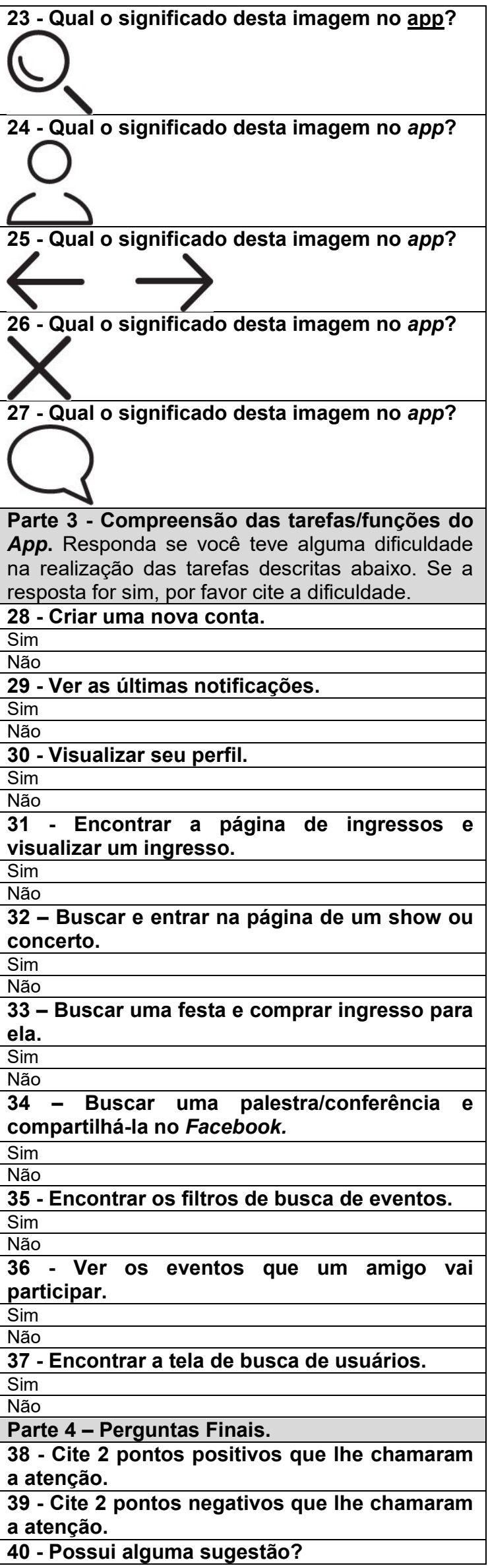


